\title{
Interaction of nucleoside diphosphate kinase B with heterotrimeric $G$ protein $\beta \gamma$ dimers: consequences on $G$ protein activation and stability
}

\author{
Thomas Wieland
}

Received: 6 October 2006 / Accepted: 20 November 2006 / Published online: 3 January 2007

(C) Springer-Verlag 2007

\begin{abstract}
It is generally accepted that G protein coupled receptors (GPCR) activate heterotrimeric G proteins by inducing a GDP/GTP exchange at the G protein $\alpha$ subunit. In addition, the transfer of high energetic phosphate by nucleoside diphosphate kinase (NDPK) and/or the $\beta$ subunit of $G$ proteins $(G \beta)$ can induce $G$ protein activation. Recent evidence suggests that the NDPK isoform B (NDPK B) forms a complex with $G \beta \gamma$ dimers. In this complex, NDPK B acts as a protein histidine kinase phosphorylating $\mathrm{G} \beta$ at histidine residue 266 (His266). The high energetic phosphoamidate bond on His266 allows for a phosphate transfer specifically onto GDP and thus local formation of GTP, which binds to and thereby activates the respective G protein $\alpha$ subunit. Apparently, this process occurs independent of the classical GPCR-induced GDP/GTP exchange at least for members of the $G_{s}$ and $G_{i}$ subfamilies of heterotrimeric $G$ proteins. By using a mutant of $G \beta_{1}$ in which His266 was replaced by Leu, it was recently demonstrated that NDPK $\mathrm{B} / \mathrm{G} \beta \gamma$-mediated $\mathrm{G}_{\mathrm{s}}$ activation contributes by about $50 \%$ to basal cAMP formation and contractility in rat cardiac myocytes. Besides its apparent role in $G$ protein activation, the complex formation of NDPK B with $G \beta \gamma$ dimers might be essential for G protein stability. Depletion of either the NDPK B orthologue or $\mathrm{G} \beta_{1}$ isoforms in zebrafish embryos led to a similar phenotype displaying contractile dysfunction in the heart accompanied by a complete loss of heterotrimeric $G$ protein expression. In conclusion, the interaction of NDKP B with
\end{abstract}

\footnotetext{
T. Wieland $(\bowtie)$

Institut für Experimentelle und Klinische Pharmakologie und

Toxikologie, Medizinische Fakultät Mannheim,

Universität Heidelberg,

Maybachstrasse 14,

D-68169 Mannheim, Germany

e-mail: thomas.wieland@pharmtox.uni-heidelberg.de
}

$\mathrm{G} \beta \gamma$ dimers might play an important role in signal transduction, and alterations in this novel pathway might be of pathophysiological importance.

Keywords Heterotrimeric $G$ proteins .

Nucleoside diphosphate kinase $\cdot \mathrm{nm} 23-\mathrm{H} 2$.

$\mathrm{G} \beta \gamma$ dimers $\cdot$ Signal transduction

\section{Introduction}

Nucleoside diphosphate kinase (NDPK) is a ubiquitous enzyme that catalyses the transfer of the $\gamma$-phosphate from nucleoside 5 '-triphosphates (NTP) to nucleoside 5 '-diphosphates (NDP) by a ping-pong mechanism involving the formation of a high energy phosphate intermediate on His118 (Morera et al. 1995; Tepper et al. 1994). Eight isoforms of NDPK encoded by the nm23 genes in humans have been identified (Lacombe et al. 2000). In mammalian tissues, the cytosolic enzyme forms heterohexamers of 17 $21 \mathrm{kDa}$ subunits (Gilles et al. 1991; Janin et al. 2000). These are composed of different combinations of the three major isoforms, NDPK A, B and C. In addition to NTP synthesis, NDPKs are involved in a variety of processes in cellular physiology, including tumour metastasis (Steeg et al. 1988), development (Rosengard et al. 1989), gene regulation (Postel 2003), apoptosis (Fan et al. 2003), endocytosis (Krishnan et al. 2001; Palacios et al. 2002), vesicular transport from the endoplasmatic reticulum (Kapetanovich et al. 2005) and regulation of the cystic fibrosis transmembrane conductance regulator (Crawford et al. 2006a).

The activity of heterotrimeric $\mathrm{G}$ proteins $(\mathrm{G} \alpha \beta \gamma)$ is controlled by G protein coupled receptors (GPCRs), and upon activation, they transduce extracellular signals to 
intracellular effectors. They consist of two functional units, the guanine nucleotide-binding $\mathrm{G} \alpha$ subunit and the $\mathrm{G} \beta \gamma$ dimer (Hamm 1998). In the inactive state, GDP is bound in the $\alpha$ subunit of the heterotrimer. Agonist-activated GPCRs induce the release of GDP upon agonist binding, and subsequently, GTP, which is present in much higher intracellular concentrations than GDP, binds to the empty nucleotide-binding pocket in $G \alpha$ (for short review, see Wieland and Michel 2005). It is generally believed that the conformational change induced by GTP binding releases the $G \beta \gamma$ dimer from the GTP-liganded $G \alpha$. Both can directly interact with specific effector proteins. Note, however, that the concept of heterotrimer dissociation has recently been challenged (Bünemann et al. 2003). After the hydrolysis of GTP to GDP and inorganic phosphate by the intrinsic GTPase activity present in $\mathrm{G} \alpha$, the $\mathrm{G}$ protein returns to its inactive heterotrimeric state. In the early 1980 s, the group of N. Kimura (for review, see Kimura 1993) were the first to show a contribution of the plasma membrane-bound fraction of NDPK to the activation of heterotrimeric G proteins by GTP formation. Thereafter, data reported by a variety of groups including the laboratory of Karl H. Jakobs (Wieland and Jakobs 1989; Jakobs and Wieland 1989; Wieland et al. 1991) supported that notion. In this paper, we will mainly focus on recent work that describes the identification of a complex formed by $G \beta \gamma$ and the NDPK B isoform and discuss its role in the activation and stability of heterotrimeric $\mathrm{G}$ proteins.

\section{GTP formation by NDPK: more than simple replenishment of $G$ protein hydrolysed GTP?}

One of the major reactions catalysed by NDPK is the phosphate transfer from ATP to GDP. This reaction, especially when catalysed by the membrane-bound fraction of NDPK, can maintain steady levels of GTP despite its constant hydrolysis during the activation of cycle of heterotrimeric $\mathrm{G}$ proteins and monomeric GTPases. Numerous in vitro studies, mainly performed in crude membrane preparations, have revealed $G$ protein activation through this enzymatic activity of NDPK (reviewed by Otero 1990, 2000; Kimura 1993; Piacentini and Niroomand 1996). Already in this early days, it was found that locally formed, NDPK-derived GTP or its poorly hydrolysable analogue GTP $\gamma \mathrm{S}$ are more potent in activating heterotrimeric $\mathrm{G}$ proteins than exogenously added GTP or GTP $\gamma$ S (Jakobs and Wieland 1989; Wieland and Jakobs 1992; Niroomand et al. 1997). Two hypotheses to explain such data have mainly been discussed: (1) substrate channelling, which in this case means local, NDPK-catalysed formation of GTP from ATP and GDP in immediate vicinity of the G protein (Kimura and Shimada 1990; Otero et al. 1988; Jakobs and Wieland 1989; Wieland et al. 1992) or (2) the transfer of the high energy phosphate intermediately present on His 118 of the NDPK directly onto the GDP still bound to the G $\alpha$ subunit of the heterotrimer or monomeric GTPases (Kikkawa et al. 1990; Randazzo et al. 1991).

\section{NDPK catalysed GTP formation on G protein bound GDP: is it possible?}

Today, it appears clear that the second hypothesis is wrong, and experimental data believed to support it were based on artefacts. Structural data obtained from crystals of purified G protein $\alpha$ subunits (Lambright et al. 1994; Mixon et al. 1995) and of the heterotrimeric G protein (Wall et al. 1995) show that the bound GDP is deeply buried in the G protein $\alpha$ subunit and even less accessible in the heterotrimer (see Fig. 1). Also, the phosphohistidine in the NDPK monomer is hidden in a small cleft within the structure (Janin et al. 2000; Lascu and Gonin 2000), and thus, a transfer of the phosphate onto GDP bound to $\mathrm{G} \alpha$ is not possible without large alterations in the three-dimensional structures. A transfer to GDP bound to monomeric GTPases is at least not likely (Scheffzek et al. 1995). The experimental artefacts mentioned above were due to a spontaneous release of GDP from G proteins. This GDP served as a substrate for phosphotransfer by the NDPK, and the formed GTP then bound back to the G protein (Randazzo et al. 1991, 1992a,b; Lutz et al. 2002). Even an approach where GDP has been cross-linked to the monomeric GTPase Rad (Zhu et al. 1999) is questionable by its experimental design (Otero 2000), as NDPK is able to transfer phosphate also onto denatured proteins and thus also on the covalently linked GDP (Engel et al. 1995).

\section{NDPK-mediated nucleotide channelling: a possible mechanism?}

The channelling of GTP into the G protein would only be possible when a close association, i.e. a complex formation of at least a monomeric NDPK molecule with the heterotrimeric $G$ protein or one of its subunits occurs. Indeed, experimental data have been reported already in the late 1980s, which support such a complex of membranous NDPK with the stimulatory G protein of adenylyl cyclase $\left(\mathrm{G}_{\mathrm{s}}\right.$; Kimura and Shimada 1988a,b, 1990) or the retinal G protein transducin $\left(\mathrm{G}_{\mathrm{t}}\right.$; Orlov et al. 1996; Klinker and Seifert 1999). Nevertheless, the contribution of local GTP formation to effector regulation was disputed or not detected in other systems (Xu et al. 1996; Sorota et al. 
Fig. 1 Three-dimensional structure of NDPK B complexed with a heterotrimeric $\mathrm{G}$ protein. Ribbon diagrams of a trimeric $\mathrm{G}$ protein $\left(\mathrm{G} \alpha_{\mathrm{s}}-\mathrm{GDP}[\mathrm{red}], \mathrm{G} \beta_{1}\right.$ [blue $]$ and $\mathrm{G} \gamma_{2}[$ yellow]) were superimposed with NDPK B (green). The possible structural vicinity of the histidine residues of NDPK B (His118, yellow) and $\mathrm{G} \beta$ (His 266, yellow) is illustrated. The phosphate is shown in red. The GDP molecule in the nucleotide binding site in $\mathrm{G} \alpha$ is depicted in green

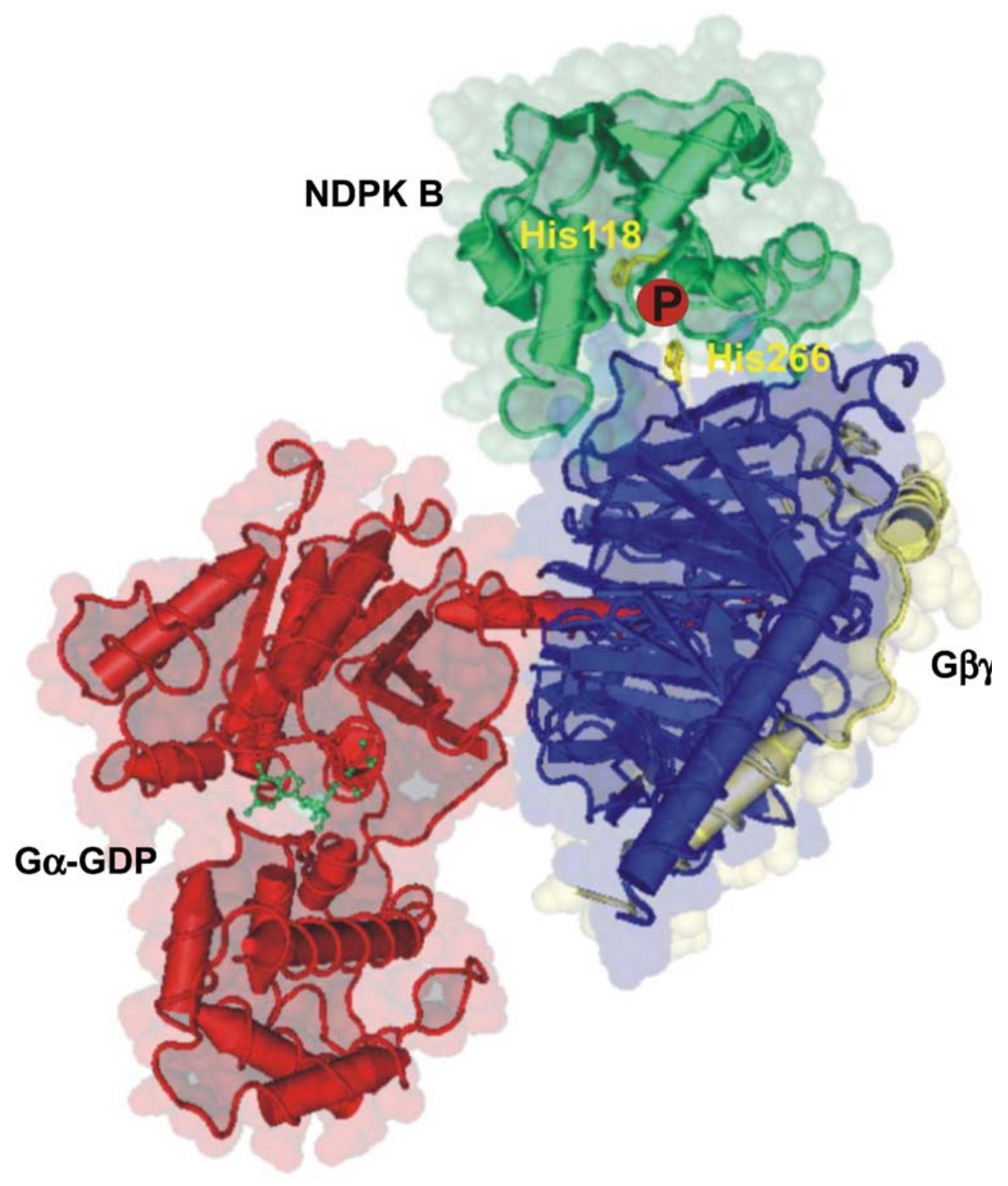

1998). The major drawback in all those studies was that the enzymatic activity of NDPK was used as a major read-out for detection of the presence of the enzyme. Due to its extremely high enzymatic activity, contaminations with small amounts of NDPK, which are still present in G protein-enriched fractions, might have led to misinterpretations, and therefore, a more specific role of NDPK than the simple replenishment of GTP from ATP and GDP has been thoroughly questioned (Otero 2000). Recent data, however, indicate that NDPK-mediated nucleotide channelling do occur by complex formation with other nucleotide consuming proteins (Crawford et al. 2005, 2006a,b). The NDPK isoform NDPK A forms a complex with the AMPactivated protein kinase $\alpha 1$ isoform (AMPK). In this complex, AMPK phosphorylates NDPK A on a serine residue and thereby regulates "substrate channelling", which in this case is shielding of NDPK-generated ATP from the consumption in the surroundings. Taking these data and the recently discovered complex formation of the NDPK B isoform with G $\beta \gamma$ dimers (Cuello et al. 2003, see below) into account, channelling of GTP at heterotrimeric $\mathrm{G}$ proteins is still the most likely hypothesis for NDPKmediated $\mathrm{G}$ protein activation.

\section{GTP formation by intermediately phosphorylated G protein $\beta$ subunits: an alternative phosphate transfer reaction?}

The group of Karl H. Jakobs was the first to report that the $\beta$ subunit of $G$ proteins can carry a high energetic phosphate (Wieland et al. 1991). This phosphate was 
characterised to be a phosphoamidate on a histidine residue, which was transferable onto GDP thus leading to GTP formation (Wieland et al. 1993), G protein activation and regulation of effector activity (Wieland et al. 1992). GDP was the only cellular NDP substrate for that phosphate transfer reaction. In contrast to the NDPK, the phosphohistidine intermediate is not formed by incubation of the protein with the required NTP but required a histidine kinase activity which phosphorylates $G \beta$ within the $G \beta \gamma$ dimer. Intermediately occurring histidine phosphorylation of $\mathrm{G} \beta$ has been detected in a variety of mammalian tissues (Nürnberg et al. 1996), including human platelets (Hohenegger et al. 1996) and rat pancreatic $\beta$ cells (Kowluru et al. 1996). The identity of the proposed membrane-bound histidine kinase to catalyse this reaction remained, however, elusive (Nürnberg et al. 1996, Kowluru 2002). Also, in this phosphotransfer reaction, the phosphorylation of GDP bound to G $\alpha$ was a matter of debate (Wieland et al. 1993; Kaldenberg-Stasch et al. 1994; Hohenegger et al. 1996; Kowluru et al. 1996; Niroomand et al. 1997). The same experimental constraints, which cannot exclude the spontaneous release of the $G \alpha$-bound GDP and re-binding of formed GTP, apply here, and some experimental data are clearly arguing against a direct transfer on G $\alpha$-bound GDP (Hohenegger et al. 1996).

\section{NDPK B, the G $\beta$ histidine kinase within the NDPK $\mathrm{B} / \mathrm{G} \beta \gamma$ dimer complex?}

The first, evidence that the histidine kinase, which phosphorylates $G \beta$, is a NDPK was presented by Cuello et al. (2003). The $G \beta$ phosphorylating activity was enriched from $G_{t}$ preparations out of bovine rod outer segments membranes and preparations of the inhibitory $G$ proteins of adenylyl cyclase $\left(\mathrm{G}_{\mathrm{i} / \mathrm{o}}\right)$ out of bovine brain membranes. Fractions in which histidine phosphorylation of $G \beta$ was enriched have been obtained by different purification protocols out of the respective source. Most interestingly, out of both tissues, these fractions contained a small amount of $G \beta \gamma$ dimers, which has been separated from the vast majority of the heterotrimeric $G$ protein, and NDPK, which could be detected by its enzymatic activity, autophosphorylation at His118 and specific antibodies. Although several NDPK isoforms are abundantly expressed in the source tissues, isoform-specific antibodies revealed a selective enrichment of NDPK B. By size exclusion chromatography, the molecular mass of the kinase activity was estimated to be 60-70 kDa. Kowluru et al. (Kowluru 2002; Kowluru et al. 2002) reported a G $\beta$ phosphorylating "histidine kinase" activity of rat pancreatic $\beta$ cells with a similar size. This kinase activity could be stimulated by the known NDPK activator mastoparan. In addition, mem- branes of these cells contained only NDPK B but not NDPK A. The estimated molecular mass of the "histidine kinase" would match with a complex formed of G $\beta \gamma$ and monomeric NDPK B (Gß 35-36 kDa, G $\gamma$ 5-12 kDa, NDPK $17-21 \mathrm{kDa})$. Indeed, a direct interaction of $\mathrm{G} \beta \gamma$ with the NDPK could be demonstrated by co-immunoprecipitation experiments (Cuello et al. 2003). A G $\beta$ as well as a NDPK B-specific antiserum precipitated both phosphorylated NDPK B plus phosphorylated G $\beta$ from the retinal preparations.

The phosphorylation of $G \beta$ could be reconstituted by combining purified $G \beta \gamma$ dimers from bovine brain or $G_{t} \beta \gamma$ with the $G \beta$ phosphorylating activity from bovine brain (Cuello et al. 2003) Therefore, radioactive labelling and subsequent proteolytic analysis of $\mathrm{G}_{t} \beta \gamma$, which consists of the isoforms $G \beta_{1}$ and $G \gamma_{1}$, as well as of less-defined bovine brain $G \beta \gamma$ dimers, were used to identify the histidine residue 266 (His266) as the phosphorylated intermediate in $\mathrm{G} \beta_{1}$. A homologous histidine residue is conserved in the mammalian $\mathrm{G} \beta_{1}-\mathrm{G} \beta_{4}$ isoforms but not in $\mathrm{G} \beta_{5}$, and only the imidazolyl side chain of this His is exposed on the surface of the G protein (see Fig. 1). All seven additional imidazolyl side chains are deeply buried in the seven-blade propeller structure of $\mathrm{G} \beta$ (Wall et al. 1995) and are therefore not likely accessible to kinases. In contrast, by superimposing the three-dimensional structure of a NDPK B monomer (Webb et al. 1995) and a heterotrimeric $G$ protein (Fig. 1), it appears structurally feasible that His 118 of the NDPK B and His 266 of G $\beta_{1}$ can come close enough to allow a phosphorelay from one histidine residue to the other. Such a phosphate transfer is well known in bacteria and used to mediate recognition of chemotactic stimuli (for review, see Falke et al. 1997).

Most important, the biochemical and structural data, which point to NDPK B acting as histidine kinase in a NDPK $B / G \beta \gamma$ complex, could be substantiated by functional data obtained from stable cell clones of immortalized neonatal rat cardiac myocytes (H10 cells; Hippe et al. 2003). In membranes of NDPK B-overexpressing H10 cells, an increase in the content and activity of NDPK B as well as the formation of NDPK B/G $\beta \gamma$ complexes was detected. When $\mathrm{G} \beta$ phosphorylation was analysed in membranes of $\mathrm{H} 10$ cells stably overexpressing NDPK A, NDPK B or its catalytically inactive mutant NDPK BH118N (H118), an increase in Phospho-G $\beta$ was observed in the NDPK B but not in the NDPK A or H118overexpressing cells. Thus, an increase in functional NDPK $\mathrm{B} / \mathrm{G} \beta \gamma$ complexes apparently increases the amount of intermediately phosphorylated $\mathrm{G} \beta$ subunits. Furthermore, adenovirus-mediated overexpression of $\mathrm{G} \beta_{1} \gamma_{2}$ dimers in the NDPK B-overexpressing H10 cells further increased $\mathrm{G} \beta$ phosphorylation by about twofold. This increase was absent when an adenovirus encoding $G \beta_{1} \gamma_{2}$ dimers 
in which His266 of $G \beta_{1}$ was mutated to leucine $\left(\mathrm{G} \beta_{1} \mathrm{H} 266 \mathrm{~L} \gamma_{2}\right)$ was used (Hippe et al. 2005).

\section{GPCR-independent $G$ protein activation by NDPK $B / G \beta \gamma$ complexes: a mechanism to regulate basal activity?}

Most of the data reporting on phosphate transfer reactions by NDPK or by G $\beta$ and the resulting G protein activation were based on studies in cell membranes or partially purified protein fractions. Therefore, they have been suspected to be the result of these artificial conditions, and their relevance for signal transduction in living cells has consequently been questioned (Hohenegger et al. 1996; Clapham and Neer 1997; Otero 2000). The cell clones of stable transfected H10 cells, which overexpress NDPK B at different levels, as well as H118 or NDPK A enabled Hippe et al. (2003) to address the question of NDPK B-mediated $\mathrm{G}$ protein activation in an intact cell model. The expressions of $G \alpha_{s}, G \alpha_{i}$ and $G \beta \gamma$ were not different between the individual cell clones, and the cellular GTP and ATP levels as well as basal cAMP formation were similar. Increasing adenoviral overexpression of the adenylyl cyclase stimulatory $\mathrm{G} \alpha$ subunit $\mathrm{G} \alpha_{\mathrm{s}}$ induced, however, huge differences in basal, GPCR-independent cAMP accumulation. Whereas cAMP accumulation increased linearly with amount of overexpressed $\mathrm{G} \alpha_{\mathrm{s}}$ in all cell clones, the slope of this linear increase, however, correlated with the amount of overexpressed NDPK B in the respective cell clone. For example, when compared to control H10 cells, the increase in cAMP levels in response to $G \alpha_{\mathrm{s}}$ was about fourfold higher at each level of $\mathrm{G} \alpha_{\mathrm{s}}$ expression in the cell clone with a threefold higher NDPK activity. The cell clone threefold, expressing the inactive NDPK B mutant H118, displayed a reduced cAMP accumulation (by about 33\%) in response to $G \alpha_{\text {s }}$ compared to control H10 cells. Overexpression of NDPK A was without effect on cAMP synthesis, which data showed that the activation of $G \alpha_{\mathrm{s}}$ was strictly dependent on the catalytic activity of the NDPK B isoform. The combined stimulatory effect of NDPK B and G $\alpha_{\mathrm{s}}$ overexpression on cAMP formation was confirmed by measurements of adenylyl cyclase activity in membranes of the H10 cell clones, linking the data in living cells to the previously disputed biochemical analyses in cell membranes (Hippe et al. 2003). Notably, like already shown in a variety of membrane systems in the early 1990s, in the H10 membrane in vitro assay, the NDPK B and $\mathrm{G} \alpha_{\mathrm{s}}$-dependent stimulation of adenylyl cyclase was largely suppressed when the phosphate acceptor substrate GDP was replaced by its analogue, guanosine 5'-O-(2-thio)diphosphate (GDP $\beta S$ ). GDP $\beta S$ binds to $G \alpha$ subunits with similar affinity than GDP but is a poor substrate for NDPK
(Niroomand et al. 1997) and Phospho-G $\beta$ (Wieland et al. 1993). Most interestingly, an even stronger reduction in $\mathrm{G} \alpha_{\mathrm{s}}$-dependent cAMP accumulation then with $\mathrm{H} 118 \mathrm{mu}-$ tant was obtained when $\mathrm{G} \beta_{1} \mathrm{H} 266 \mathrm{~L} \gamma_{2}$ was adenovirally overexpressed in H10 cells. Compared to the overexpression of wild-type $G \beta_{1} \gamma_{2}$, cells overexpressing comparable levels of $\mathrm{G} \alpha_{\mathrm{s}}$ and $\mathrm{G} \beta_{1} \mathrm{H} 266 \mathrm{~L} \gamma_{2}$ exhibited about $55 \%$ lower cAMP levels (Hippe et al. 2005). Similar data were obtained by comparison of adenoviral overexpression of wild-type $\mathrm{G} \beta_{1} \gamma_{2}$ and $\mathrm{G} \beta_{1} \mathrm{H} 266 \mathrm{~L} \gamma_{2}$ in cultured neonatal rat cardiac myocytes. When an identical approach was used in isolated adult rat ventricular cardiomyocytes and single cell fractional shortening was measured, overexpression of $\mathrm{G} \beta_{1} \mathrm{H} 266 \mathrm{~L} \gamma_{2}$ but not of wild-type $\mathrm{G} \beta_{1} \gamma_{2}$ significantly reduced myocyte contractility. In contrast, overexpression of either $G \beta_{1} \mathrm{H} 266 \mathrm{~L} \gamma_{2}$ or wild-type $G \beta_{1} \gamma_{2}$ similarly supported $\beta$-adrenoceptor-induced cAMP synthesis and increase in contractility in $\mathrm{H} 10$ cells, neonatal and adult rat ventricular myocytes. Therefore, all this functional data provide evidence for a physiological relevance of NDPKmediated G protein activation in GPCR-independent, basal activation of $G$ proteins in living cells (Fig. 2). Like a variety of proteins, e.g. dynamin I, phocein (Baillat et al. 2002), ICAP $\alpha$ (Fournier et al. 2002), KSR (Hartsough et al. 2002) and AMPK (Crawford et al. 2005, 2006b), G $\beta \gamma$ dimers form a complex with a specific isoform of NDPK, which in case of heterotrimeric G proteins is NDPK B. At least one additional, so far unidentified, protein appears to be required and might function as scaffold for this complex (Cuello et al. 2003). This subpopulation of $G$ protein complexed with NDPK B can be activated by a phosphate transfer: In the living cell, most likely, ATP binds to the NDPK B as NTP substrate in that complex and its $\gamma$ phosphate is transferred onto His118 in the NDPK B. Acting as protein histidine kinase, this high energetic phosphate is transferred onto His 266 in $G \beta$. Out of that phosphoamidate bond, the phosphate is transferred specifically onto GDP, and the formed GTP leads to receptor-independent $G$ protein activation. At present, the experimental data support such a model for $G_{s}, G_{t}$ and other members of the $\mathrm{G}_{\mathrm{i}}$ family. A contribution of NDPKmediated $G$ protein activation for members of the $G_{q}$ or $G_{12}$ families of $G$ proteins has not been reported yet. As already discussed above, experimental evidence as well as the three-dimensional structure of a heterotrimeric $G$ Protein (Fig. 1) does not support a direct transfer onto $G \alpha$-bound GDP. The distance between His266 and the bound GDP molecule within the $G \alpha$ subunit is far too large to allow such a transfer. Nevertheless, it appears feasible that the GDP bound in $\mathrm{G} \alpha$ dissociates with a certain frequency from the binding pocket and thus comes in close proximity to Phospho-His266 in G $\beta$. The phosphate is transferred onto that GDP, and the newly formed GTP can bind with 
Fig. 2 GPCR-dependent and alternative NDPK B-dependent G protein activation. Agonist binding to a GPCR triggers GDP/GTP exchange on $\mathrm{G} \alpha$ and release of $\mathrm{G} \beta \gamma$, leading to effector responses (left side). In the subpopulation of heterotrimeric $\mathrm{G}$ proteins complexed with NDPK B, a phosphotransfer from NTP, preferably ATP, to His 118 in NDPK B and subsequently onto His 266 of $\mathrm{G} \beta$, results in a high energetic phosphate, which promotes the formation of GTP, leading to GPCR-independent $\mathrm{G}$ protein activation and thus regulation of basal effector activities. Two possible mechanisms modulating this pathway are shown. Increased plasma membrane content of NDPK B, as detected in CHF will increase basal $\mathrm{G}$ protein activity. Phosphohistidine phosphatase $(P H P)$, which can specifically dephosphorylate $G \beta$, is a potential counter regulator of NDKP Bdependent $\mathrm{G}$ protein activation

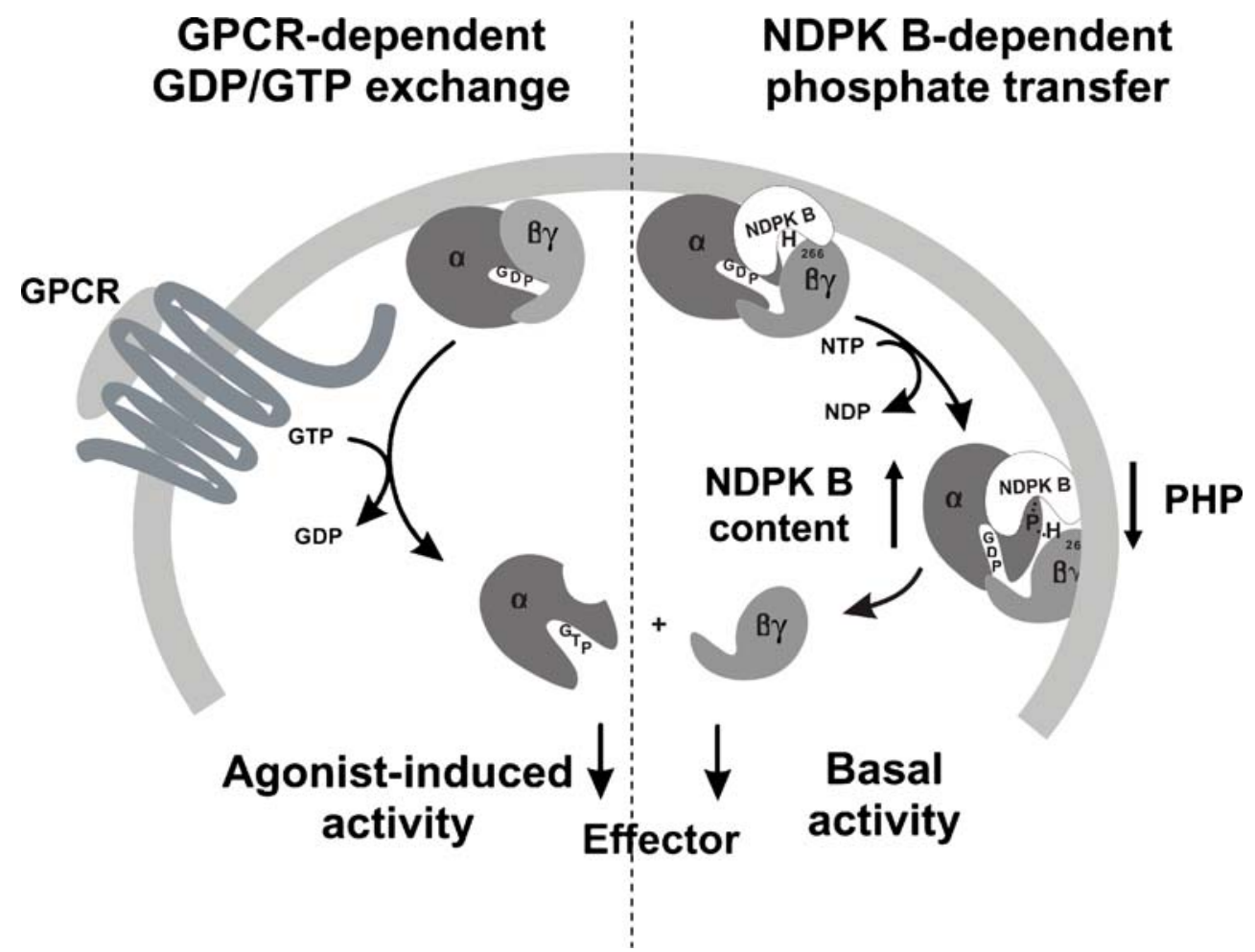

high affinity to the still empty binding pocket. Thus, the G protein will be activated. This model would explain many of the data obtained in membranes during the 1980s and 1990 s and as discussed above, allow for the "old" hypothesis of GTP channelling in which the NDPK-formed GTP is shielded from the surroundings and thus has an advantage.

In a recent report (Mäurer et al. 2005), it was described that the first identified mammalian phosphohistidine phosphatase (PHP; Ek et al. 2002; Klumpp et al. 2002) is able to dephosphorylate $G \beta$, but not NDPK $B$, in reconstituted systems and in $\mathrm{H} 10$ cells membranes. Its stable overexpression in living $\mathrm{H} 10$ cells also interferes with $\mathrm{G} \beta$ phosphorylation. Therefore, PHP might be an endogenous regulator of basal NDPK-dependent G protein activation. Apparently, it targets the formation of Phospho-His266 in $\mathrm{G} \beta$ (see Fig. 2), the importance of which has been proven by mutation analysis.

\section{Stimulation of phosphorelay by agonist-liganded GPCRs: more than an interesting hypothesis?}

From the purification of the NDPK $B / G \beta \gamma$ complexes (Cuello et al. 2003), it was, however, concluded that the majority of $\mathrm{G}$ proteins is not complexed with NDPK B. These $G$ proteins still can be activated by the classical pathway of GPCR-induced GDP/GTP exchange. Nevertheless, a variety of data accumulated by different laboratories in the early days of investigations on NDPK and $\mathrm{G}$ protein activation (reviewed in Otero 1990; Piacentini and Niroomand 1996) as well as some data on $G$ protein activation by phosphorylated $G \beta$ subunits (Kaldenberg-Stasch et al. 1994) argued for a role of phosphate transfer in GPCR-induced G protein activation. These speculations culminated in a hypothesis in which the GPCR/G protein complex functions as GTP synthase and a phosphorelay would be the essential mechanism of $\mathrm{G}$ protein activation (Nederkoorn et al. 1998). Besides the fact that these data were only based on theoretical calculations, the formation of a phosphohistidine on His 183 of $G \beta$ was crucial to this hypothesis. The identification of His 266 as the phosphorylated His in $G \beta$ and the structural impossibility to relay this phosphate to His 183 are arguing against this phosphorelay hypothesis. Also, the experimental data so far accumulated in studying the influence of $\mathrm{G} \beta_{1} \mathrm{H} 266 \mathrm{~L} \gamma_{2}$ on $\beta$-adrenoceptor-induced cAMP synthesis and contractility (Hippe et al. 2005) do not support a role of NDPK B/ $\mathrm{G} \beta \gamma$ complexes in GPCR-induced G protein activation In addition, measurement of isoproterenol-stimulated GTP $\gamma \mathrm{S}$ binding in membranes of Sf9 insect cells (Kühn et al. 2002) in which the human $\beta_{2}$-adrenoceptor was reconstituted with $\mathrm{G} \alpha_{\mathrm{s}}$ and either wild-type $\mathrm{G} \beta_{1} \gamma_{2}$ or with $\mathrm{G} \beta_{1} \mathrm{H} 266 \mathrm{~L} \gamma_{2}$ by baculovirus infection revealed no difference between wildtype and mutant $G \beta \gamma$. Both equally supported agoniststimulated GTP $\gamma \mathrm{S}$ binding. Therefore, a direct stimulation of NDPK $B / G \beta \gamma$-mediated phosphate transfer by agonistliganded GPCRs is not very likely. 


\section{NDPK B/G $\beta \gamma$ complexes: are they required for $G$ protein stability in vivo?}

The data so far summarised did not address the question whether the formation of NDPK B/G $\beta \gamma$ complexes are of physiological relevance for $G$ protein-mediated signal transduction in a living, multicellular organism. A recent attempt used the morpholino phosphorodiamidate oligonucleotide-induced gene depletion in zebrafish embryos (Sumanas and Larson 2002, Iversen and Newbry 2005) to study this issue (Mehringer et al. 2006). A selective knockdown of the zebrafish orthologues of the NDPK isoforms $A$ and $B$ as well as $G \beta_{1}$ subunits was made by injection of specific morpholino antisense oligos compared to control embryos injected with scrambled oligos. Depletion of NDPK B, but not NDPK A, led to severely compromised atrial and ventricular cardiac function associated with pericardial edema and insufficient blood flow. Histology and immunofluorescence staining revealed intact development and no structural defects in the knockdown hearts. The knockdown of the two zebrafish $G \beta_{1}$ ortho-

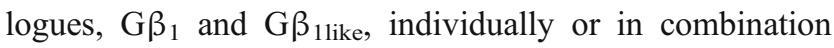
caused a very similar phenotype with an identical cardiac dysfunction. As a consequence of the NDPK B depletion, a nearly complete loss of $\mathrm{G} \beta_{1}$ and $\gamma_{2}$ proteins was detected. Vice versa, the depletion of $G \beta_{1 / 1 \text { like }}$ was associated with the specific loss of the NDKP B orthologue. Most interestingly, in the NDPK B as well as in the $G \beta_{1 / 1 \text { like }}$ knockdown animals, the expression of the $\mathrm{G} \alpha$ subunits of all four $G$ protein subfamilies, $G_{s}, G_{i}, G_{q}$ and $G_{12}$, was almost completely suppressed. In contrast, the expression of several other marker proteins was unaffected, and only the content of the mRNA encoding the targeted protein was strongly reduced. A similar loss of all $\mathrm{G} \alpha$ subunits was recently reported for small interfering RNA-induced silencing of $G \beta_{1}$ and $G \beta_{2}$ in J774A.1 mouse macrophages (Hwang et al. 2005). In summary, the data point to an enhanced posttranslational degradation of heterotrimeric $G$ proteins or their remaining components when either the NDKP $B$ or $G \beta_{1}$ as important contributors in the protein complex are missing. For the first time, they provide in vivo evidence for an essential role of the interaction of NDPK B with $G \beta \gamma$ dimers to maintain $G$ protein expression and thus normal cardiac contractility.

\section{NDPK-G protein interaction: are there alterations in disease?}

Besides the rather huge amount of literature dealing with the tumour suppressor function of NDPK (for review, see Steeg et al. 2003), very little information about alterations in other diseases is available. A contribution of the phosphate transfer by NDPK $\mathrm{B} / \mathrm{G} \beta \gamma$ complexes was so far implicated in diabetes and congestive heart failure (CHF).

The notion that $G$ protein activation via NDPK B/G $\beta \gamma$ complexes might be altered in diabetes are based on findings in Goto-Kakizaki rats, a model for human type 2 diabetes, which exhibit impaired insulin secretion in response to glucose. These animals display a reduction of about $50 \%$ in NDPK activity (Metz et al. 1999), NDPK autophosphorylation and histidine kinase activity compared to control rats (Kowluru 2003). In addition, it was recently shown that some polyunsaturated fatty acids, which are well-known stimulators of insulin secretion, increase NDPK activity, NDPK autophosphorylation and G $\beta$ phosphorylation in rat pancreatic islet cells (Kowluru 2004).

The notion that NDPK/G $\beta \gamma$-mediated G protein activation is altered in CHF, is based on findings demonstrating an at least threefold higher content in sarcolemmal membranes purified from human myocardium of failing hearts compared to non-failing controls (Lutz et al. 2001; Zhou and Artman 2001). These changes were only seen in the small pool of membrane-associated NDPK and were not observed in either homogenate, cytosol or other remaining fractions. These data, therefore, suggested a translocation from the cytosol to the plasma membrane in cardiac myocytes. An up-regulation of all three major isoforms (NDPK A, B and C) was detectable (Lutz et al. 2004), which is likely due to the formation of heterohexamers by the majority of the NDPK isoforms (Gilles et al. 1991). Furthermore, a substantial GPCR-independent inhibition of adenylyl cyclase activity up to $50 \%$ in membranes of failing hearts was demonstrated. These data, therefore, support the above-outlined role of NDPK B/G $\beta \gamma$ complex as modulator of basal $G$ protein activity. Interestingly, the net effect of the NDPK B-mediated regulation of adenylyl cyclase activity in failing hearts was an inhibition, which obviously correlates to the relative prevalence of $\mathrm{G} \alpha_{\mathrm{i}}$ in CHF (Neumann et al. 1988). In contrast, in sarcolemmal membranes of canine hearts, NDPK stimulates adenylyl cyclase via $G \alpha_{\mathrm{s}}$ (Niroomand et al. 1997). Thus, it is tempting to speculate that at $\mathrm{G} \alpha_{\mathrm{s}}$ and $\mathrm{G} \alpha_{\mathrm{i}}$ subunits nonselectively form heterotrimers with NDPK $B / G \beta \gamma$ complexes, and thereby, any alteration in the prevalence of the one or the other $\mathrm{G} \alpha$ subunit decides whether the net effect is receptor-independent stimulation $\left(\mathrm{G} \alpha_{\mathrm{s}}\right.$ prevalence) or inhibition $\left(\mathrm{G} \alpha_{\mathrm{i}}\right.$ prevalence) of adenylyl cyclase activity. Thereby, this mechanism might aggravate the consequence of a rather small (30-50\%) increase in $\mathrm{G} \alpha_{\mathrm{i}}$ in CHF and contribute to the well-known diminished cAMP signalling observed in failing hearts.

The use of $\beta$-adrenoceptor antagonists is meanwhile part of the accepted standard therapy in CHF (Lohse et al. 2003). Interestingly, the elevation of the membrane-associ- 
ated NDPK was partially prevented in patients with CHF, which have been treated with $\beta$-adrenoceptor antagonists. On the other hand, the progression of cardiac hypertrophy induced by chronic $\beta$-adrenoceptor stimulation was paralleled by the increase in membrane-associated NDPK (Lutz et al. 2003). In contrast, an increase in NDPK content was not observed when hypertrophy was induced with thyroid hormone. Consistent with recent reports showing NDPK translocation by stimulation of GPCRs (Gallagher et al. 2003; Rochdi et al. 2004), these data suggest that sustained stimulation of $\beta$-adrenergic receptors increases association of NDPK with the plasma membrane. Taking the recent findings in the zebrafish into account, the primary regulation might occur at the level of mRNA encoding the interacting $G$ protein $\alpha$ subunit (Müller et al. 1994). By a formation of stable heterotrimers of the translated protein with NDPK $\mathrm{B} / \mathrm{G} \beta \gamma$ complexes, this might cause the enhanced association of NDPK with the plasma membrane without transcriptional regulation of the NDPK B itself.

\section{Conclusion}

Over the last 25 years, a large body of work has been accumulated, which now gives evidence for an important role of the interaction of NDPK with heterotrimeric G proteins. The primary observations, which have been disputed for a long time due to a methodology prone to artefacts, have recently been substantiated by studies in living cells and whole organisms. Although we have not finally solved the question of the physiological and pathophysiological function of NDPK $\mathrm{B} / \mathrm{G}$ protein complexes yet, we meanwhile obtained a raw picture and certainly, directions in which we have to look further.

Besides the complexation of heterotrimeric $G$ proteins with NDPK B on which this review is focused and the welldocumented interactions with GPCRs and effectors, it is meanwhile clear that the additional proteins like regulators of G proteins (for review, see Wieland and Mittmann 2003, Abramow-Newerly et al. 2006), scaffold proteins (Chen et al. 2004; Wang et al. 2005), membrane organising proteins like caveolins (Head et al. 2005) and even proteins, which were, until now, believed not to be interaction partners of heterotrimeric $G$ proteins, e.g. endothelial nitric oxide synthase (Andreeva et al. 2006), a part of cellular signal transduction machineries. Thus, we are far away from understanding the complexity of heterotrimeric $G$ proteinmediated signal transduction pathways on the cellular level. Also, generally accepted mechanisms on how heterotrimeric $\mathrm{G}$ proteins principally operate have been questioned lately. A recent report raised the question whether $\mathrm{G}$ proteins have to be in the GTP-bound form to be active (Ugur et al. 2005; Wieland and Michel 2005), and there is increasing evidence that not all heterotrimeric $G$ proteins dissociate into $\mathrm{G} \alpha$ and $\mathrm{G} \beta \gamma$ upon activation (Bünemann et al. 2003; Frank et al. 2005). Taking further into account that, in in vitro systems, even nucleotide-free $\mathrm{G} \alpha$ subunits are active (Lutz et al. 2002), or heterotrimeric G proteins can be activated by pyrimidine nucleotide triphosphates under conditions excluding high energy phosphate relay (Gille et al. 2005), it is evident that investigations on heterotrimeric $\mathrm{G}$ proteins and their interaction partners, like those performed by Karl H. Jakobs since 1970 (Jakobs and Schultz 1970), will provide interesting and relevant topics for several decades of future research.

Acknowledgments The work of T.W. reported herein was supported by grants of the Deutsche Forschungsgemeinschaft. Out of the many coworkers and collaborators with significant contributions on the $\mathrm{NDPK} / \mathrm{G} \beta \gamma$ project, the names of those who received a M.D. or Ph.D. degree under supervision of Prof. Karl H. Jakobs shall be mentioned here to his honour: Jens Bremerich, Marita Osterheider, Marina Ronzani, Sylvia Kaldenberg-Stasch, Michael Baden, Rüdiger Schulze and Frank Heemeyer.

This review is dedicated to Professor Karl H. Jakobs. Twenty years ago, he initiated a scientific career by bringing this topic into my life. I am deeply grateful for his guidance and the still ongoing and fruitful collaborations with him.

\section{References}

Abramow-Newerly M, Roy AA, Nunn C, Chidiac P (2006) RGS proteins have a signalling complex: interactions between RGS proteins and GPCRs, effectors, and auxiliary proteins. Cell Signal 18:579-591

Andreeva AV, Vaiskunaite R, Kutuzov MA, Profirovic J, Skidgel RA, Voyno-Yasenetskaya T (2006) Novel mechanisms of G proteindependent regulation of endothelial nitric-oxide synthase. Mol Pharmacol 69:975-982

Baillat G, Gaillard S, Castets F, Monneron A (2002) Interactions of phocein with nucleoside-diphosphate kinase, Eps15, and dynamin I. J Biol Chem 277:18961-18966

Bünemann M, Frank M, Lohse MJ (2003) $G_{i}$ protein activation in intact cells involves subunit rearrangement rather than dissociation. Proc Natl Acad Sci USA 100:16077-16082

Chen S, Spiegelberg BD, Lin F, Dell EJ, Hamm HE (2004) Interaction of G $\beta \gamma$ with RACK1 and other WD40 repeat proteins. J Mol Cell Cardiol 37:399-406

Clapham DE, Neer EJ (1997) G protein $\beta \gamma$ subunits. Annu Rev Pharmacol Toxicol 37:167-203

Crawford RM, Treharne KJ, Best OG, Muimo R, Riemen CE, Mehta A (2005) A novel physical and functional association between nucleoside diphosphate kinase A and AMP-activated protein kinase $\alpha 1$ in liver and lung. Biochem J 392:201-209

Crawford RM, Treharne KJ, Arnaud-Dabernat S, Daniel JY, Foretz M, Viollet B, Mehta A (2006a) Understanding the molecular basis of the interaction between NDPK-A and AMPK $\alpha 1$. Mol Cell Biol 26:5921-5931

Crawford RM, Treharne KJ, Best OG, Riemen CE, Muimo R, Gruenert DC, Arnaud-Dabernat S, Daniel JY, Mehta A (2006b) NDPK-A (but not NDPK-B) and AMPK $\alpha 1$ (but not AMPK $\alpha 2$ ) bind the cystic fibrosis transmembrane conductance regulator in epithelial cell membranes. Cell Signal 18:1595-1603 
Cuello F, Schulze RA, Heemeyer F, Meyer HE, Lutz S, Jakobs KH, Niroomand F, Wieland T (2003) Activation of heterotrimeric G proteins by a high energy phosphate transfer via nucleoside diphosphate kinase (NDPK) B and $\beta$ subunits. Complex formation of NDPK B with G $\beta \gamma$ dimers and phosphorylation of His-266 in G $\beta$. J Biol Chem 278:7220-7226

Ek P, Pettersson G, Ek B, Gong F, Li JP, Zetterqvist O (2002) Identification and characterization of a mammalian $14-\mathrm{kDa}$ phosphohistidine phosphatase. Eur J Biochem 269:5016-5023

Engel M, Veron M, Theisinger B, Lacombe ML, Seib T, Dooley S, Welter C (1995) A novel serine/threonine-specific protein phosphotransferase activity of Nm23/nucleoside-diphosphate kinase. Eur J Biochem 234:200-207

Falke JJ, Bass RB, Butler SL, Chervitz SA, Danielson MA (1997) The two-component signaling pathway of bacterial chemotaxis: a molecular view of signal transduction by receptors, kinases, and adaptation enzymes. Annu Rev Cell Dev Biol 13:457-512

Fan Z, Beresford PJ, Oh DY, Zhang D, Lieberman J (2003) Tumor suppressor NM23-H1 is a granzyme A-activated DNase during CTL-mediated apoptosis, and the nucleosome assembly protein SET is its inhibitor. Cell 112:659-672

Fournier HN, Dupe-Manet S, Bouvard D, Lacombe ML, Marie C, Block MR, Albiges-Rizo C (2002) Integrin cytoplasmic domainassociated protein $1 \alpha$ (ICAP- $1 \alpha)$ interacts directly with the metastasis suppressor $\mathrm{nm} 23-\mathrm{H} 2$, and both proteins are targeted to newly formed cell adhesion sites upon integrin engagement. J Biol Chem 277:20895-20902

Frank M, Thumer L, Lohse MJ, Bünemann M (2005) G Protein activation without subunit dissociation depends on a $\mathrm{G} \alpha_{\mathrm{i}}$-specific region. J Biol Chem 280:24584-24590

Gallagher BC, Parrott KA, Szabo G, de Otero SA (2003) Receptor activation regulates cortical, but not vesicular localization of NDP kinase. J Cell Sci 116:3239-3250

Gille A, Guo J, Mou TC, Doughty MB, Lushington GH, Seifert R (2005) Differential interactions of G-proteins and adenylyl cyclase with nucleoside 5 -triphosphates, nucleoside $5{ }^{\prime}-[\gamma-$ thio]triphosphates and nucleoside $5^{\prime}-[\beta, \gamma$-imido]triphosphates. Biochem Pharmacol 71:89-97

Gilles AM, Presecan E, Vonica A, Lascu I (1991) Nucleoside diphosphate kinase from human erythrocytes. Structural characterization of the two polypeptide chains responsible for heterogeneity of the hexameric enzyme. J Biol Chem 266:8784-8789

Hamm HE (1998) The many faces of G protein signaling. J Biol Chem 273:669-672

Hartsough MT, Morrison DK, Salerno M, Palmieri D, Ouatas T, Mair M, Patrick J, Steeg PS (2002) Nm23-H1 metastasis suppressor phosphorylation of kinase suppressor of Ras via a histidine protein kinase pathway. J Biol Chem 277:32389-32399

Head BP, Patel HH, Roth DM, Lai NC, Niesman IR, Farquhar MG, Insel PA (2005) G-protein-coupled receptor signaling components localize in both sarcolemmal and intracellular caveolin-3associated microdomains in adult cardiac myocytes. J Biol Chem 280:31036-31044

Hippe HJ, Lutz S, Cuello F, Knorr K, Vogt A, Jakobs KH, Wieland T, Niroomand F (2003) Activation of heterotrimeric G proteins by a high energy phosphate transfer via nucleoside diphosphate kinase (NDPK) $B$ and $G \beta$ subunits. Specific activation of $\mathrm{G}_{\mathrm{s}} \alpha$ by an

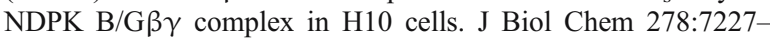
7233

Hippe HJ, Meissl F, Luedde M, Lutz S, Wieland T, Niroomand F (2005) Inhibition of receptor-independent cAMP synthesis and contractility of cardiomyocytes by mutation of His-266-phosphorylation of $G$ protein $\beta$ subunits. Circulation 112(Suppl II): 116

Hohenegger M, Mitterauer T, Voss T, Nanoff C, Freissmuth M (1996) Thiophosphorylation of the $G$ protein beta subunit in human platelet membranes: evidence against a direct phosphate transfer reaction to $\mathrm{G} \alpha$ subunits. Mol Pharmacol 49:73-80

Hwang JI, Choi S, Fraser ID, Chang MS, Simon MI (2005) Silencing the expression of multiple $\mathrm{G} \beta$-subunits eliminates signaling mediated by all four families of $\mathrm{G}$ proteins. Proc Natl Acad Sci USA 102:9493-9498

Iversen PL, Newbry S (2005) Manipulation of zebrafish embryogenesis by phosphorodiamidate morpholino oligomers indicates minimal non-specific teratogenesis. Curr Opin Mol Ther 7:104 108

Jakobs KH, Schultz G (1970) Effects of various hormones and drugs on adenyl cyclase of rat kidney. Naunyn Schmiedebergs Arch Pharmacol 266:364-365

Jakobs KH, Wieland T (1989) Evidence for receptor-regulated phosphotransfer reactions involved in activation of the adenylate cyclase inhibitory $\mathrm{G}$ protein in human platelet membranes. Eur J Biochem 183:115-121

Janin J, Dumas C, Morera S, Xu Y, Meyer P, Chiadmi M, Cherfils J (2000) Three-dimensional structure of nucleoside diphosphate kinase. J Bioenerg Biomembranes 32:215-225

Kaldenberg-Stasch S, Baden M, Fesseler B, Jakobs KH, Wieland T (1994) Receptor-stimulated guanine-nucleotide-triphosphate binding to guanine-nucleotide-binding regulatory proteins. Nucleotide exchange and $\beta$-subunit-mediated phosphotransfer reactions. Eur J Biochem 221:25-33

Kapetanovich L, Baughman C, Lee TH (2005) Nm23H2 facilitates coat protein complex II assembly and endoplasmic reticulum export in mammalian cells. Mol Biol Cell 16:835-848

Kikkawa S, Takahashi K, Takahashi K, Shimada N, Ui M, Kimura N, Katada T (1990) Conversion of GDP into GTP by nucleoside diphosphate kinase on the GTP-binding proteins. J Biol Chem 265:21536-21540

Kimura N (1993) Role of nucleoside diphosphate kinase in G protein action. Handbook of experimental pharmacology. In: Dickey BF, Birnbaumer L (eds) GTPases in Biology, vol 108/II. Springer, Berlin Heidelberg New York, pp 485-496

Kimura N, Shimada N (1988a) Direct interaction between membraneassociated nucleoside diphosphate kinase and GTP-binding protein $\left(\mathrm{G}_{\mathrm{s}}\right)$, and its regulation by hormones and guanine nucleotides. Biochem Biophys Res Commun 151:248-256

Kimura N, Shimada N (1988b) Membrane-associated nucleoside diphosphate kinase from rat liver. Purification, characterization, and comparison with cytosolic enzyme. J Biol Chem 263:46474653

Kimura N, Shimada N (1990) Evidence for complex formation between GTP binding protein $\left(\mathrm{G}_{\mathrm{s}}\right)$ and membrane-associated nucleoside diphosphate kinase. Biochem Biophys Res Commun 168:99-106

Klinker JF, Seifert R (1999) Nucleoside diphosphate kinase activity in soluble transducin preparations: biochemical properties and possible role of transducin- $\beta$ as phosphorylated enzyme intermediate. Eur J Biochem 261:72-80

Klumpp S, Hermesmeier J, Selke D, Baumeister R, Kellner R, Krieglstein J (2002) Protein histidine phosphatase: a novel enzyme with potency for neuronal signaling. J Cereb Blood Flow Metab 22:1420-1424

Kowluru A (2002) Identification and characterization of a novel protein histidine kinase in the islet beta cell: evidence for its regulation by mastoparan, an activator of G-proteins and insulin secretion. Biochem Pharmacol 63:2091-2100

Kowluru A (2003) Defective protein histidine phosphorylation in islets from the Goto-Kakizaki diabetic rat. Am J Physiol Endocrinol Metab 285:E669-E684

Kowluru A (2004) Differential regulation by fatty acids of protein histidine phosphorylation in rat pancreatic islets. Mol Cell Biochem 266:175-182 
Kowluru A, Seavey SE, Rhodes CJ, Metz SA (1996) A novel regulatory mechanism for trimeric GTP-binding proteins in the membrane and secretory granule fractions of human and rodent beta cells. Biochem J 313:97-108

Kowluru A, Tannous M, Chen HQ (2002) Localization and characterization of the mitochondrial isoform of the nucleoside diphosphate kinase in the pancreatic beta cell: evidence for its complexation with mitochondrial succinyl-CoA synthetase. Arch Biochem Biophys 398:160-169

Krishnan KS, Rikhy R, Rao S, Shivalkar M, Mosko M, Narayanan R, Etter P, Estes PS, Ramaswami M (2001) Nucleoside diphosphate kinase, a source of GTP, is required for dynamin-dependent synaptic vesicle recycling. Neuron 30:197-210

Kühn B, Christel C, Wieland T, Schultz G, Gudermann T (2002) Gprotein $\beta \gamma$-subunits contribute to the coupling specificity of the $\beta_{2}$-adrenergic receptor to $G(s)$. Naunyn Schmiedebergs Arch Pharmacol 365:231-241

Lacombe ML, Milon L. Munier A, Mehus JG, Lambeth DO (2000) The human NM23/nucleoside diphosphate kinases J. Bionerg Biomembr 32:247-258

Lambright DG, Noel JP, Hamm HE, Sigler PB (1994) The 2.0 A crystal structure of a heterotrimeric G protein. Nature 369:621-628

Lascu I, Gonin P (2000) The catalytic mechanism of nucleoside diphosphate kinases. J Bioenerg Biomembranes 32:237-246

Lohse MJ, Engelhardt S, Eschenhagen T (2003) What is the role of beta-adrenergic signaling in heart failure? Circ Res 93:896-906

Lutz S, Mura R, Baltus D, Movsesian M, Kübler W, Niroomand F (2001) Increased activity of membrane-associated nucleoside diphosphate kinase and inhibition of cAMP synthesis in failing human myocardium. Cardiovasc Res 49:48-55

Lutz S, Baltus D, Jakobs KH, Niroomand F (2002) Spontaneous release of GDP from $\mathrm{G}_{i}$ proteins and inhibition of adenylyl cyclase in cardiac sarcolemmal membranes. Naunyn Schmiedebergs Arch Pharmacol 365:50-55

Lutz S, Mura RA, Hippe HJ, Tiefenbacher C, Niroomand F (2003) Plasma membrane-associated nucleoside diphosphate kinase $(\mathrm{nm} 23)$ in the heart is regulated by $\beta$-adrenergic signalling. $\mathrm{Br}$ J Pharmacol 140:1019-1026

Lutz S, Hippe HJ, Niroomand F, Wieland T (2004) Nucleoside diphosphate kinase-mediated activation of heterotrimeric $\mathrm{G}$ proteins. Methods Enzymol 390:403-418

Mäurer A, Wieland T, Meissl F, Niroomand F, Mehringer R, Krieglstein J, Klumpp S (2005) The $\beta$-subunit of G proteins is a substrate of protein histidine phosphatase. Biochem Biophys Res Commun 334:1115-1120

Mehringer R, Hippe HJ, Rauch GJ, Niroomand F, Wieland T, Rottbauer W (2006) Contractile dysfunction of the embryonic zebrafish heart after knockdown of the nucleoside diphosphate kinase $\mathrm{B}$ or the $\mathrm{G}$ protein $\beta_{1}$-subunit. Clin Res Cardiol 95 (Suppl 5):V676

Metz AS, Meredith M, Vadakekalam, J, Rabaglia ME, Kowluru A (1999) A defect late in stimulus-secretion coupling impairs insulin secretion in Goto-Kakizaki diabetic rats. Diabetes 48:1756-1762

Mixon MB, Lee E, Coleman DE, Berghuis AM, Gilman AG, Sprang SR (1995) Tertiary and quaternary structural changes in $G_{i} \alpha_{1}$ induced by GTP hydrolysis. Science 270:954-960

Morera S, Chiadmi M, LeBras G, Lascu I, Janin J (1995) Mechanism of phosphate transfer by nucleoside diphosphate kinase: X-ray structures of the phosphohistidine intermediate of the enzymes from Drosophila and Dictyostelium. Biochemistry 34:1106211070

Müller FU, Eschenhagen T, Reidemeister A, Schmitz W, Scholz H (1994) In vivo $\beta$-adrenergic stimulation leads to biphasic regulation of $\mathrm{G}_{\mathrm{i}} \alpha_{2}$ gene transcriptional activity in rat heart. $\mathrm{J}$ Mol Cell Cardiol 26:869-875
Nederkoorn PJ, Timmerman H, Timms D, Wilkinson AJ, Kelly DR, Broadley KJ, Davies RH (1998) Stepwise phosphorylation mechanisms and signal transmission within a ligand-receptorG $\alpha \beta \gamma$-protein-complex. J Mol Struct 452:25-47

Neumann J, Schmitz W, Scholz H, von Meyerinck L, Doring V, Kalmar P (1988) Increase in myocardial $\mathrm{G}_{\mathrm{i}}$-proteins in heart failure. Lancet 2:936-937

Niroomand F, Mura R, Jakobs KH, Rauch B, Kübler W (1997) Receptor-independent activation of cardiac adenylyl cyclase by GDP and membrane-associated nucleoside diphosphate kinase. A new cardiotonic mechanism? J Mol Cell Cardiol 29:1479-1486

Nürnberg B, Harhammer R, Exner T, Schulze RA, Wieland T (1996) Species- and tissue-dependent diversity of G-protein beta subunit phosphorylation: evidence for a cofactor. Biochem J 318:717-722

Orlov NY, Orlova TG, Nomura K, Hanai N, Kimura N (1996) Transducin-mediated, isoform-specific interaction of recombinant rat nucleoside diphosphate kinases with bleached bovine retinal rod outer segment membranes. FEBS Lett 389:186-190

Otero AD (1990) Transphosphorylation and G protein activation. Biochem Pharmacol 39:1399-1404

Otero AS (2000) NM23/nucleoside diphosphate kinase and signal transduction. J Bioenerg Biomembranes 32:269-275

Otero AS, Breitwieser GE, Szabo G (1988) Activation of muscarinic potassium currents by ATP $\gamma \mathrm{S}$ in atrial cells. Science 242:443-445

Palacios F, Schweitzer JK, Boshans RL, D'Souza-Schorey C (2002) ARF6-GTP recruits Nm23-H1 to facilitate dynamin-mediated endocytosis during adherens junctions disassembly. Nat Cell Biol 4:929-936

Piacentini L, Niroomand F (1996) Phosphotransfer reactions as a means of $G$ protein activation. Mol Cell Biochem 157:59-63

Postel EH (2003) Multiple biochemical activities of NM23/NDP kinase in gene regulation. J Bioenerg Biomembranes 35:31-40

Randazzo PA, Northup JK, Kahn RA (1991) Activation of a small GTP-binding protein by nucleoside diphosphate kinase. Science 254:850-853

Randazzo PA, Kahn RA, Northup JK (1992a) Nucleoside diphosphate kinase: conclusions withdrawn. Science 257:862

Randazzo PA, Northup JK, Kahn RA (1992b) Regulatory GTPbinding proteins (ADP-ribosylation factor, $G_{t}$, and RAS) are not activated directly by nucleoside diphosphate kinase. J Biol Chem 267:18182-18189

Rochdi MD, Laroche G, Dupre E, Giguere P, Lebel A, Watier V, Hamelin E, Lepine MC, Dupuis G, Parent JL (2004) Nm23-H2 interacts with a $\mathrm{G}$ protein-coupled receptor to regulate its endocytosis through an Rac1-dependent mechanism. J Biol Chem 279:18981-18989

Rosengard AM, Krutzsch HC, Shearn A, Biggs JR, Barker E, Margulies IM, King CR, Liotta LA, Steeg PS (1989) Reduced $\mathrm{Nm} 23 /$ Awd protein in tumour metastasis and aberrant Drosophila development. Nature 342:177-180

Scheffzek K, Klebe C, Fritz-Wolf K, Kabsch W, Wittinghofer A (1995) Crystal structure of the nuclear RAS-related protein Ran in its GDP-bound form. Nature 37:378-381

Sorota S, Chlenov M, Du XY, Kagan M (1998) ATP-dependent activation of the atrial acetylcholine-induced $\mathrm{K}+$ channel does not require nucleoside diphosphate kinase activity. Circ Res 82:971-979

Steeg PS, Bevilacqua G, Kopper L, Thorgeirsson UP, Talmadge JE, Liotta LA, Sobel ME (1988) Evidence for a novel gene associated with low tumor metastatic potential. J Natl Cancer Inst 80:200-204

Steeg PS, Palmieri D, Ouatas T, Salerno M (2003) Histidine kinases and histidine phosphorylated proteins in mammalian cell biology, signal transduction and cancer. Cancer Lett 190:1-12

Sumanas S, Larson JD (2002) Morpholino phosphorodiamidate oligonucleotides in zebrafish: a recipe for functional genomics? Brief Funct Genomic Proteomic 1:239-256 
Tepper AD, Dammann H, Bominaar AA, Veron M (1994) Investigation of the active site and the conformational stability of nucleoside diphosphate kinase by site-directed mutagenesis. J Biol Chem 269:32175-32180

Ugur O, Oner SS, Molinari P, Ambrosio C, Sayar K, Onaran HO (2005) Guanine nucleotide exchange-independent activation of $\mathrm{G}_{\mathrm{s}}$ protein by $\beta_{2}$-adrenoceptor. Mol Pharmacol 68:720-728

Wall MA, Coleman DE, Lee E, Iniguez-Lluhi JA, Posner BA, Gilman AG, Sprang SR (1995) The structure of the G protein heterotrimer $\mathrm{G}_{\mathrm{i}} \alpha_{1} \beta_{1} \gamma_{2}$. Cell 83:1047-1058

Wang X, Zeng W, Soyombo AA, Tang W, Ross EM, Barnes AP, Milgram SL, Penninger JM, Allen PB, Greengard P, Muallem S (2005) Spinophilin regulates $\mathrm{Ca}^{2+}$ signalling by binding the Nterminal domain of RGS2 and the third intracellular loop of Gprotein-coupled receptors. Nat Cell Biol 7:405-411

Webb PA, Perisic O, Mendola CE, Backer JM, Williams RL (1995) The crystal structure of a human nucleoside diphosphate kinase, NM23-H2. J Mol Biol 251:574-587

Wieland T, Jakobs KH (1989) Receptor-regulated formation of GTP $[\gamma \mathrm{S}]$ with subsequent persistent $\mathrm{G}_{\mathrm{s}}$-protein activation in membranes of human platelets. FEBS Lett 245:189-193

Wieland T, Jakobs KH (1992) Evidence for nucleoside diphosphokinasedependent channeling of guanosine $5^{\prime}-(\gamma$-thio)triphosphate to guanine nucleotide-binding proteins. Mol Pharmacol 42:731-735

Wieland T, Michel MC (2005) Can a GDP-liganded G-protein be active? Mol Pharmacol 68:559-562
Wieland T, Mittmann C (2003) Regulators of G-protein signalling: multifunctional proteins with impact on signalling in the cardiovascular system. Pharmacol Ther 97:95-115

Wieland T, Ulibarri I, Gierschik P, Jakobs KH (1991) Activation of signal-transducing guanine-nucleotide-binding regulatory proteins by guanosine $5^{\prime}$-[ $\gamma$-thio $]$ triphosphate. Information transfer by intermediately thiophosphorylated $\beta \gamma$ subunits. Eur J Biochem 196:707-716

Wieland T, Ronzani M, Jakobs KH (1992) Stimulation and inhibition of human platelet adenylylcyclase by thiophosphorylated transducin $\beta \gamma$-subunits. J Biol Chem 267:20791-20797

Wieland T, Nürnberg B, Ulibarri I, Kaldenberg-Stasch S, Schultz G, Jakobs KH (1993) Guanine nucleotide-specific phosphate transfer by guanine nucleotide-binding regulatory protein $\beta$-subunits. Characterization of the phosphorylated amino acid. J Biol Chem 268:18111-18118

$\mathrm{Xu} \mathrm{L}$, Murphy J, Otero AS (1996) Participation of nucleosidediphosphate kinase in muscarinic $\mathrm{K}^{+}$channel activation does not involve GTP formation. J Biol Chem 271:21120-21125

Zhou YY, Artman M (2001) Nucleoside diphosphate kinase: a new player in heart failure? Cardiovasc Res 49:7

Zhu J, Tseng YH, Kantor JD, Rhodes CJ, Zetter BR, Moyers JS, Kahn CR (1999) Interaction of the Ras-related protein associated with diabetes Rad and the putative tumor metastasis suppressor NM23 provides a novel mechanism of GTPase regulation. Proc Natl Acad Sci USA 96:14911-14918 